\title{
Supportive interventions and their impact on pediatric health care professionals' emotional well-being: A systematic literature review
}

\author{
Christina Melin-Johansson ${ }^{1}$, Annika Day ${ }^{2}$, Inge Axelsson ${ }^{1,}{ }^{3}$, I ngela Forslund ${ }^{4}$ \\ 1. Department of Nursing Sciences, Mid Sweden University, Östersund, Sweden. 2. Neonatal Clinic, Danderyd Hospital, \\ Sweden. 3. Child and Adolescent Medicine, Östersund Hospital, Östersund, Sweden. 4. Child and Adolescent Medicine, \\ Helsingborg Hospital, Sweden.
}

Correspondence: Christina Melin-J ohansson. Address: Mid Sweden University, SE83125, Östersund, Sweden. Email: titti.melin-johansson@miun.se

Received: June 15, 2014

Accepted: July 25, 2014

Online Published: August 26, 2014

DOI : $10.5430 /$ cns.v2n4p60

URL: http://dx.doi.org/10.5430/cns.v2n4p60

\section{Abstract}

The aim of this systematic literature review was to describe interventions supporting pediatric health care professionals to manage emotional strain when caring for children at the end-of-life. The review included five quantitative studies. Two categories were identified within the results: 1) Supportive interventions with the subcategories of educational interventions, peer support for grief, intensive training course, peer supported storytelling, and debriefing sessions; and 2) Effects of interventions, with the subcategories of increased understanding, increased confidence, creating meaning, grief management, and sense of well-being. Interventions that combine education and dialogue seem supportive, but debriefing might have the most impact on health care professionals' emotional well-being. Future research should focus on deepening the understanding of the meaning of education and dialogue for health care professionals, further investigate the effects of debriefing, and focus on educational training around existential issues.

\section{Key words}

Children, Health care staff, Nursing, Palliative care, Support

\section{Introduction}

In Western culture, it is considered unnatural for children to die. It is taken for granted that everyone should live a long life and that parents should survive their children. A family who is about to lose a child faces unimaginable situations and experiences; it is the worst thing that can happen. A child's death has devastating effects on the entire family and generates problems in relationships, difficulty adjusting to a new family situation, and depression ${ }^{[1]}$. To care for a child for whom a cure is not possible demands the knowledge, understanding, and compassion of health care professionals. It affects them in their professional practice and on a personal level ${ }^{[2-5]}$.

\subsection{Background}

A universally accepted strategy for palliative care for adults was defined in 1990 by the World Health Organization [WHO]. In 1998, a similar strategy was defined for children and this definition embodies a special, albeit closely related, 
field to adult palliative care in that the principles apply to additional pediatric chronic disorders. Palliative care for children is described as the active total care of the child's body, mind and soul, as well as ways in which to support the family. Palliative care for children starts when the disease is diagnosed and continues regardless of whether or not a child receives treatment directed at the disease ${ }^{[6]}$. Globally, 160,000 cases of cancer were identified in children younger than 15 years of age, and 90,000 die every year ${ }^{[7]}$. In Sweden, traffic accidents are the leading cause of death, followed by cancer. About $0.3 \%$ of children and adolescents are diagnosed with cancer; eight out of ten survive the disease. In 2012, 69 children and adolescents in Sweden under the age of 20 died of cancer (ICD 10, diagnoses C00D48) ${ }^{[8]}$. Three out of four children in Sweden died in hospital. The most common cancers were brain tumors and leukemia ${ }^{[9]}$.

The process that takes place when a child dies makes a significant impact and often contributes to work-related stress regardless of the professional's medical specialty ${ }^{[3,10,11]}$. Health care professionals experience moral and ethical stress when asked to perform actions that contradict their personal and professional values about what is right ${ }^{[4]}$ or when nursing staff's and the parents' opinions differ on what is best for the child ${ }^{[3]}$. Moral distress occurs when staff cannot put their moral choices into action. This leads to feelings of personal pain, anger, resentment, guilt, sadness, frustration, futility, and powerlessness, which undermine the health professional's integrity, self-esteem, and personal maturity ${ }^{[2-5,12,19]}{ }^{\text {. Many }}$ have sleep disturbances, feel irritable and emotionally drained and on the edge of burnout, and find it difficult to "forget" their work in their free time; many must take sick leave for work-related stress ${ }^{[3]}$.

Caring for children with cancer may contribute to severe fatigue from physiological and psychological stressors because these children live with pain and suffering for a long period of time ${ }^{[13,14]}$. Psychological stress triggers cortisol secretion in the blood of health care professionals, but extensive experience in the profession does not lower cortisol levels over time ${ }^{[15,16]}$. However, the more experience health care professionals as nurses have in the profession, the better they cope with difficult situations and the less frequent the feeling of hopelessness. Health care professionals who care for children with life-threatening diseases other than cancer describe that the symptoms creating the most concern due to pain and suffering occur when the child is not communicating, when there are problems of a psychiatric or psychological nature, or when there are problems with the assessment and treatment of pain, seizures, and vomiting ${ }^{[17]}$. Caring for a dying child increases health care professionals' awareness of their own personal losses and vulnerabilities and increases their anxiety and stress levels ${ }^{[4]}$. However, such caregiving evokes not only negative feelings but can also be beneficial and give a sense of purpose to life and can lead to personal growth ${ }^{[18]}$.

When a child has died, health care professionals begin a grieving process that alternates between feeling and avoiding the pain caused by the loss. This allows them to process their experiences of death ${ }^{[5]}$. Others feel compelled to put grief aside to immediately return to work without having the opportunity to talk about what they have experienced. Further, professionals experience a lack of emotional, psychological, and social support from colleagues and management ${ }^{[2,4]}$ despite expressing a need to talk with others about their experiences to vent their emotions ${ }^{[2]}$. They try to protect themselves from unwanted feelings by keeping themselves busy with other tasks ${ }^{[2,12]}$.

Emotionally, it is very stressful to take part in a child's illness and death ${ }^{[2,3]}$. Health care professionals often become emotionally drained and on the edge of burnout. Besides the subjective suffering, there is also a risk that they will distance themselves from the child and family in order to protect themselves emotionally. Supportive methods to reduce stress and improve coping strategies are important. Without prevention and management of health care professionals' emotional reactions, the quality of care and efficiency will be affected. This review is relevant to identify supportive interventions available to health care professionals in pediatric palliative care so that they can be emotionally available when they are caring for children in the palliative phase. This review will be the basis for the development of future interventions in the field. 


\subsection{Aim}

The aim of this systematic literature review was to describe interventions supporting pediatric health care professionals to manage emotional strain when caring for children at the end-of-life.

\section{Methods and ethical considerations}

\subsection{Design}

A systematic literature review method (The PRISMA Statement) ${ }^{[20]}$ was utilized to confirm, extend, and/or refute empirical studies. Literature searches were made in a number of databases with a focus on medicine and nursing with the purpose of identifying relevant articles within the area ${ }^{[21]}$.

\subsection{Sample}

Inclusion criteria: Published articles written in English describing interventions with the overall aim of improving and developing care, increasing staff skills, and improving working conditions were included; they addressed children aged 0-18 years, palliative care, and interventions directed toward health care professionals' well-being. No restrictions were made concerning the date of publication.

Exclusion criteria: Articles that involved those caring for adults in palliative care were excluded, as were national health care programs on pediatric palliative care or other education/interventions where the primary purpose was not to support and assist health care professionals who care for seriously ill children.

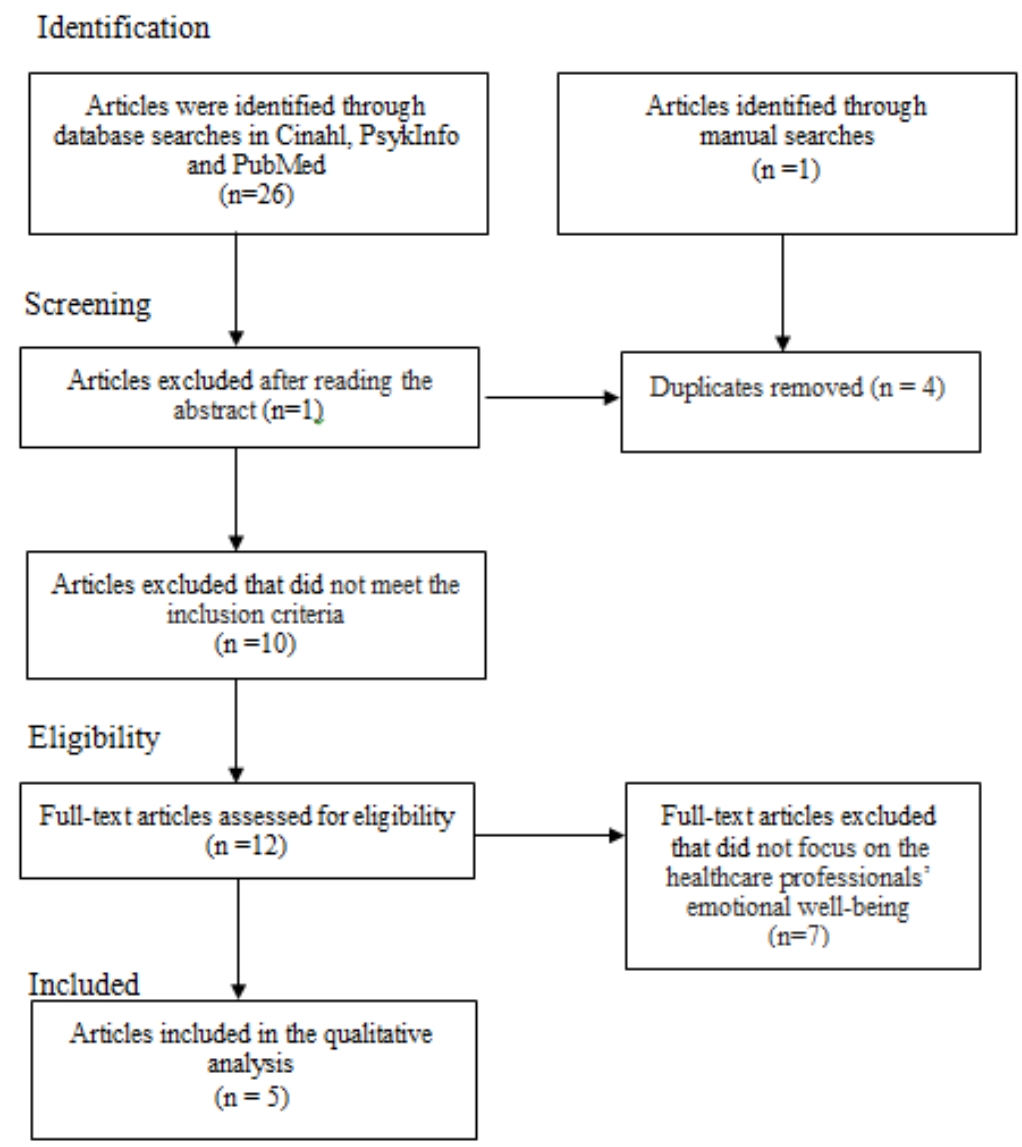

Figure 1. Flow diagram of literature search procedure 
Table 1. Overview of included articles regarding the aim, design, main results, categories and grade of quality

\begin{tabular}{|c|c|c|c|c|c|}
\hline $\begin{array}{l}\text { Author, } \\
\text { year and } \\
\text { country }\end{array}$ & $\begin{array}{l}\text { The aim of the } \\
\text { intervention }\end{array}$ & $\begin{array}{l}\text { Design, sample, content of the } \\
\text { intervention, and method of } \\
\text { analysis }\end{array}$ & Main results & $\begin{array}{l}\text { Subcategories } \\
\text { as presented in } \\
\text { the results }\end{array}$ & $\begin{array}{l}\text { Grade of quality } \\
\text { DS = descriptive } \\
\text { studies (N=5) } \\
\text { Grade I = high } \\
\text { quality } \\
\text { Grade II = } \\
\text { medium quality } \\
\text { Grade III = low } \\
\text { quality }\end{array}$ \\
\hline $\begin{array}{l}\text { Eagle, } \\
\text { Creel h\& } \\
\text { Alexandrov } \\
\text { Eagle et al. }{ }^{[25]} \\
\text { USA }\end{array}$ & $\begin{array}{l}\text { Measuring levels of } \\
\text { sadness, stress, and } \\
\text { burnout and evaluating } \\
\text { the effect of peer } \\
\text { support for grief and } \\
\text { burnout }\end{array}$ & $\begin{array}{l}\text { Quantitative method } \\
\text { Pilot Study } \\
\text { Clinicians from a plurality } \\
\text { professionals in a pediatric intensive } \\
\text { care unit ( } \mathrm{N}=28 \text { ) } \\
\text { The intervention consisted of two } \\
\text { training sessions on grief, coping } \\
\text { strategies, peer support, and basic } \\
\text { philosophies of pediatric palliative } \\
\text { care } \\
\text { Pre-post test instruments: } \\
\text { Copenhagen Burnout Inventory and } \\
\text { the Hogan Grief Reaction Checklist }\end{array}$ & $\begin{array}{l}\text { No statistically } \\
\text { significant effect of } \\
\text { the method of peer } \\
\text { support intervention } \\
\text { for health } \\
\text { professionals' } \\
\text { experience of grief } \\
\text { and burnout. }\end{array}$ & $\begin{array}{l}\text { Peer support for } \\
\text { grief } \\
\text { Grief } \\
\text { management } \\
\text { Sense of } \\
\text { well-being }\end{array}$ & DS II \\
\hline $\begin{array}{l}\text { Keene, } \\
\text { Hutton, Hall } \\
\& \\
\text { Rushton. }^{[28]} \\
\text { USA }\end{array}$ & $\begin{array}{l}\text { To investigate the } \\
\text { effectiveness of } \\
\text { debriefing as a method } \\
\text { for providing support } \\
\text { to health-care } \\
\text { professionals and } \\
\text { helping them manage } \\
\text { grief after the death of } \\
\text { a child }\end{array}$ & $\begin{array}{l}\text { Quantitative method } \\
\text { Participants were health } \\
\text { professionals from several } \\
\text { disciplines at a children's hospital } \\
\text { (N = 676) } \\
\text { Questionnaires were designed for } \\
\text { this intervention in which } \\
\text { participants had to indicate how } \\
\text { useful, instructive, and meaningful } \\
\text { debriefing had been. } \\
\text { Anonymous questionnaires before } \\
\text { and after the intervention with the } \\
\text { intent to find out how debriefing } \\
\text { affects nursing staff's ability to deal } \\
\text { with grief and maintain their } \\
\text { professional integrity. }\end{array}$ & $\begin{array}{l}\text { Nursing staff } \\
\text { reported that the } \\
\text { debriefing was } \\
\text { useful (98.4\%), } \\
\text { educational (97.8\%), } \\
\text { and meaningful } \\
\text { (97.8\%). } \\
\text { The results showed } \\
\text { that the more } \\
\text { debriefings health } \\
\text { professionals } \\
\text { participated in the } \\
\text { better they managed } \\
\text { the grief after a child } \\
\text { has died. }\end{array}$ & $\begin{array}{l}\begin{array}{l}\text { Debriefing } \\
\text { sessions }\end{array} \\
\text { Increased } \\
\text { understanding } \\
\text { Creating } \\
\text { meaning } \\
\text { Grief } \\
\text { management } \\
\text { Sense of } \\
\text { well-being }\end{array}$ & DS III \\
\hline $\begin{array}{l}\text { Macpherson } \\
\text { CF. }{ }^{[27]} \\
\text { USA }\end{array}$ & $\begin{array}{l}\text { To investigate } \\
\text { 1) the exchange of } \\
\text { support nurses give } \\
\text { each other with } \\
\text { "peer-supported } \\
\text { storytelling” } \\
\text { 2) the impact } \\
\text { storytelling has on } \\
\text { nurses' grief } \\
\text { 3) the impact of } \\
\text { storytelling has on } \\
\text { nurses' sense of } \\
\text { purpose } \\
\text { 4) what content talks } \\
\text { with storytelling had }\end{array}$ & $\begin{array}{l}\text { Mixed method (quantitative and } \\
\text { qualitative) } \\
\text { Nurses at a pediatric oncology } \\
\text { section }(\mathrm{N}=6) \\
\text { The intervention consisted of two } \\
\text { occasions of storytelling where } \\
\text { nurses in pairs acted as both narrator } \\
\text { and listener } \\
\text { Qualitative content analysis } \\
\text { Instrument: } \\
\text { Hogan Grief Reaction Checklist and } \\
\text { Inventory of Social Support }\end{array}$ & $\begin{array}{l}\text { No statistically } \\
\text { significant } \\
\text { difference between } \\
\text { storytelling and } \\
\text { nurses' grief and } \\
\text { sense of purpose. } \\
\text { The participants } \\
\text { themselves reported } \\
\text { that they both } \\
\text { received and assisted } \\
\text { in storytelling } \\
\text { sessions and that it } \\
\text { helped them deal } \\
\text { with their grief. }\end{array}$ & $\begin{array}{l}\text { Peer supported } \\
\text { storytelling } \\
\text { Creating } \\
\text { meaning } \\
\text { Grief } \\
\text { management } \\
\text { Sense of } \\
\text { well-being }\end{array}$ & DS III \\
\hline
\end{tabular}


Table 1. (Continued.)

\begin{tabular}{|c|c|c|c|c|c|}
\hline $\begin{array}{l}\text { Author, } \\
\text { year and } \\
\text { country }\end{array}$ & $\begin{array}{l}\text { The aim of the } \\
\text { intervention }\end{array}$ & $\begin{array}{l}\text { Design, sample, content of the } \\
\text { intervention and method of } \\
\text { analysis }\end{array}$ & Main results & $\begin{array}{l}\text { Subcategori } \\
\text { es as } \\
\text { presented in } \\
\text { the results }\end{array}$ & $\begin{array}{l}\text { Grade of quality } \\
\text { DS= descriptive } \\
\text { studies (N=5) } \\
\text { Grade I = high } \\
\text { quality } \\
\text { Grade II= } \\
\text { medium quality } \\
\text { Grade III= low } \\
\text { quality }\end{array}$ \\
\hline $\begin{array}{l}\text { Rogers, } \\
\text { Babgi \& } \\
\text { Gomez. }{ }^{[24]} \\
\text { USA }\end{array}$ & $\begin{array}{l}\text { To evaluate whether } \\
\text { neonatal nurses who } \\
\text { care for dying } \\
\text { infants get more } \\
\text { knowledge and feel } \\
\text { more secure through } \\
\text { a training program }\end{array}$ & $\begin{array}{l}\text { Quantitative method } \\
\text { Participants were nurses in a } \\
\text { neonatal intensive care unit ( } \mathrm{N}=82 \text { ) } \\
\text { The intervention consisted of a } \\
\text { training program with } 6 \text { parts } \\
\text { 1) pain management } \\
\text { 2) symptom management } \\
\text { 3) ethical / legal issues } \\
\text { 4) communication / culture } \\
\text { 5) spirituality / anxiety } \\
\text { 6) prevention of emotional } \\
\text { exhaustion } \\
\text { A pre-and post-test instrument } \\
\text { Comfort in Caring for Dying Infants } \\
\text { was used }\end{array}$ & $\begin{array}{l}\text { Statistically significant, } \\
\text { participants who } \\
\text { completed all modules in } \\
\text { the training program } \\
\text { increased their security } \\
\text { when caring for dying } \\
\text { infants. } \\
\text { Statistical significance of } \\
\text { increased knowledge and } \\
\text { greater self-confidence } \\
\text { within the individual } \\
\text { modules' ethical / legal } \\
\text { issues and symptom } \\
\text { management. }\end{array}$ & $\begin{array}{l}\text { Educational } \\
\text { intervention } \\
\text { Increased } \\
\text { understanding } \\
\text { Increased } \\
\text { confidence }\end{array}$ & DSII \\
\hline $\begin{array}{l}\text { Rushton, } \\
\text { Reder, Hall, } \\
\text { Comello, } \\
\text { Sellers \& } \\
\text { Hutton. }{ }^{[26]} \\
\text { USA }\end{array}$ & $\begin{array}{l}\text { To implement and } \\
\text { evaluate a quality } \\
\text { improvement } \\
\text { program with the } \\
\text { intention to increase } \\
\text { the skills, } \\
\text { confidence, and } \\
\text { ability to deal with } \\
\text { personal grief in } \\
\text { professionals who } \\
\text { care for terminally ill } \\
\text { children }\end{array}$ & $\begin{array}{l}\text { Quantitative method } \\
\text { Participants were health } \\
\text { professionals active in the fields of } \\
\text { pediatric intensive care, neonatal } \\
\text { intensive care, and pediatric } \\
\text { oncology ( } \mathrm{N} \text { = 950) } \\
\text { The intervention included four parts: } \\
\text { 1) Establishment of interdisciplinary } \\
\text { networks } \\
\text { 2) Cases related to training in } \\
\text { palliative care } \\
\text { 3) Patient care conferences around } \\
\text { individual patients } \\
\text { 4) Debriefing } \\
\text { Evaluation with questionnaires } \\
\text { specifically designed for each } \\
\text { method 1-4 }\end{array}$ & $\begin{array}{l}\text { Nursing staff reported } \\
\text { that the first two } \\
\text { components of the } \\
\text { program increased } \\
\text { knowledge and safety in } \\
\text { their professional role. } \\
\text { The third intervention } \\
\text { was perceived as } \\
\text { supportive and } \\
\text { informative. } \\
\text { The fourth intervention } \\
\text { resulted in greater } \\
\text { understanding of the } \\
\text { importance of good } \\
\text { communication with } \\
\text { colleagues and relatives, } \\
\text { increased team spirit and } \\
\text { developed coping } \\
\text { strategies. }\end{array}$ & $\begin{array}{l}\begin{array}{l}\text { Intensive } \\
\text { training } \\
\text { course }\end{array} \\
\text { Increased } \\
\text { understanding } \\
\text { Creating } \\
\text { meaning } \\
\text { Sense of } \\
\text { well-being }\end{array}$ & DS III \\
\hline
\end{tabular}

\subsection{Literature searches}

Searches were conducted in Cinahl, PsycInfo, and PubMed in February 2013. Searches in the Cochrane Library yielded no relevant results. Articles were included if they focused on pediatric palliative care, described interventions directed 
towards and supporting health care professionals' well-being , and were written in English. The keywords children, death, education, end-of-life care, experiences, health care staff, improve, interventions, needs, nurse, palliative care, pediatric, support, terminal care, grief and bereavement were chosen, and the filter 'child 0-18 years' were used. The keywords were used in various combinations as both medical subject headings (MeSH) terms, Cinahl headings and as free text. Twenty-two articles were identified initially within the context of pediatric palliative care. The abstracts were read and the reference lists of these articles were reviewed which generated one additional article. Searches were then made on all articles in Web of Science, as well as by individual authors in the reference lists, but this generated no more articles. A flow diagram demonstrating the design of the search according to the PRISMA Statement (20) is presented in Figure 1.

The five articles included in the study's results were found in PubMed (1), Cinahl (1), PsycInfo (2), and manually (1); all came from United States; and all used quantitative methods. One of the articles used mixed methods (quantitative and qualitative) (see Table 1).

\subsection{Classification and measurement of included articles}

The quality of the articles was reviewed, evaluated, and classified according to the Swedish Council on Health Technology Assessment [SBU] ${ }^{[22]}$. A rating scale was used to assess the quality of articles, where I stands for high quality, II for medium quality, and III for low quality. Articles were valued exclusively as quantitative descriptive studies (DS). For an article to achieve high quality (I) it required a large, well-described, and consecutive sample, an analysis carried out using appropriate statistical methods, and a longitudinal method. Low-quality studies (III) described the sample inadequately, conducted the analysis with inadequate statistical methods, and provided inadequate follow-up. Studies assessed with grade II were studies that did not meet the criteria for either grade I or III. Assessments of the quality of the articles are presented in Table 1. To further ensure the rigor of the review process, a template for quantitative studies was used ${ }^{[23]}$.

\subsection{Analysis}

The five articles included were read several times by the authors. All texts regarding the interventions and their content and the outcomes of the same were subsequently translated from English into Swedish. The analysis was guided by the research questions: "What does this study tell us about pediatric health care professionals' supportive needs when caring for dying children and their families? and "What impact has the interventions on their well-being?" The translated text was inserted into a Word document in a random order, and unnecessary text was removed in order to make the content in the text as clear as possible. The text was then sorted into two preliminary categories describing the interventions and the effects of the interventions. The text in the categories was read several times with the intention of finding common patterns and was sorted into preliminary subcategories. All authors discussed the preliminary categories and subcategories and further sorted relevant content according to similarities and differences. This resulted in the identification of two categories with 10 subcategories that described the interventions' various content and methods, and the outcomes and impact of different interventions.

\section{Results}

This review shows that existing supportive interventions within the context of pediatric palliative care are insufficient and of medium or low quality. A majority of the studies utilized quasi-experimental descriptive methods in different pediatric care contexts. One article used mixed methods, which was an advantage because the qualitative descriptions provided additional information about participants' experiences. The intervention studies were few and primarily person-focused and no interventions were directed towards care organizations as a whole. The review resulted in a compilation of five studies and is presented in two categories and ten subcategories (see Table 2). To understand the results in the context in which they were carried out and how the articles can be classified into the categories: "Supportive interventions in pediatric palliative care" with five subcategories comprising educational intervention, peer support for grief, intensive training course, peer supported storytelling, and debriefing sessions; and "Effects of interventions" with five subcategories comprising increased understanding, increased confidence, creating meaning, grief management, and 
sense of well-being. Articles were published in the United States between 2008 and 2012 and included nurses in neonatal intensive care $(n=82)$, intensive care $(n=28)$, or oncology $(n=6)$. Further, physicians, nurses, and other health care professionals in primarily oncology, pediatric intensive care, and neonatal intensive care were included $(\mathrm{n}=1,654)$. A total of 1,770 participants were included.

Table 2. Overview of categories and subcategories and articles related to each category and sub-category

\begin{tabular}{|c|c|c|}
\hline Categories $(\mathrm{N}=2)$ & Subcategories $(\mathbf{N}=10)$ & $\begin{array}{l}\text { Articles related to each category and } \\
\text { subcategory }(\mathrm{N}=5)\end{array}$ \\
\hline \multirow{5}{*}{$\begin{array}{l}\text { Supportive interventions in } \\
\text { pediatric palliative care }\end{array}$} & Educational intervention & Rogers et al. ${ }^{[24]}$ \\
\hline & Peer support for grief & Eagle et al. ${ }^{[25]}$ \\
\hline & Intensive training course & Rushton et al., ${ }^{[26]}$ \\
\hline & Peer supported storytelling & Macpherson ${ }^{[27]}$ \\
\hline & Debriefing sessions & Keene et al., ${ }^{[28]}$ \\
\hline \multirow{5}{*}{ Effects of interventions } & Increased understanding & $\begin{array}{l}\text { Keene et al., }{ }^{[28]} ; \text { Rogers et al., }{ }^{[24]} \text {; } \\
\text { Rushton et al., }{ }^{[26]}\end{array}$ \\
\hline & Increased confidence & Rogers et al., ${ }^{[24]}$ \\
\hline & Creating meaning & $\begin{array}{l}\text { Keene et al., }{ }^{[28]} \text {; Macpherson }{ }^{[27]} \text {; } \\
\text { Rushton et al., }{ }^{[26]}\end{array}$ \\
\hline & Grief management & $\begin{array}{l}\text { Eagle, }{ }^{[25]} \text {; Keene et al., }{ }^{[28]} \text {; } \\
\text { Macpherson, }{ }^{[27]}\end{array}$ \\
\hline & Sense of well-being & $\begin{array}{l}\text { Eagle, }{ }^{[25]} \text {; Keene et al., }{ }^{[28]} \text {; } \\
\text { Macpherson, }{ }^{[27]} \text {; Rushton et al., }{ }^{[26]}\end{array}$ \\
\hline
\end{tabular}

\subsection{Supportive interventions in pediatric palliative care}

The interventions described in this category included five different educational support programs and methods evaluated with several validated questionnaires directed at health care professionals in neonatal palliative care, pediatric intensive care unit, a children's hospital, a pediatric oncology department and to health care professionals in a child health care center.

\subsubsection{Educational intervention}

One of the five studies describing interventions that supported health care professionals in managing emotional strain was an educational program geared toward neonatal palliative care divided into six modules, each with different themes ${ }^{\text {[24] }}$. Measurements were taken before and after training with the instrument "Comfort in Caring for Dying Infants" (CCDI), which comprised 15 statements about the participants' comfort levels when caring for dying infants. The scoring ranged from 15 to 75. A Likert-scale was used, graded from 1 to 5, with 1 representing "never” and 5 "always."

\subsubsection{Peer support for grief}

In the second study, an intervention was designed to measure the levels of sadness, stress, and burnout among nursing staff in a pediatric intensive care unit and to evaluate the effect of peer support for grief and burnout ${ }^{[25]}$. Measurements were taken before and after two training sessions on grief, coping strategies, peer support, and basic philosophies of pediatric palliative care using the instrument "Copenhagen Burnout Inventory" (CBI), which comprises three scales measuring personal burnout, work-related burnout, and client-related burnout, and the "Hogan Grief Reaction Checklist” (HGRC), measuring the multidimensional nature of the bereavement process including six subscales: despair (13 items), panic behavior (14 items), blame and anger (7 items), detachment (8 items), disorganization (7 items), and personal growth (8 items). A 5-point Likert-scale was used and items in each subscale were summarized. 


\subsubsection{I ntensive training course}

A third study with a supportive intervention described a quality improvement program at a children's hospital for health care professionals from a variety of disciplines, containing four parts ${ }^{[26]}$. 1) A network was established with participants from different professions. The intention was to provide a forum for shared knowledge exchange and to serve as a liaison to the profession and workplace. Participants were offered an intensive training course, and they discussed how palliative care could be integrated for a particular patient, what the strengths and challenges were, and ways to identify and document the goals of palliative care. 2) Training with patient cases in which participants identified the patient's palliative care needs from a holistic perspective. Each training session ended with the compilation of the main content and what participants brought with them into contact with future patients. Often health care professionals elevated their emotional needs. 3) Patient care conferences with the purpose of summarizing the illness, identifying issues and needs related to the child, family, and caregivers, and establishing a treatment plan. 4) Debriefing for health care professionals when a patient died. The contents of each session of the above parts was documented in writing and analyzed together with questionnaires (not described in detail) using open questions.

\subsubsection{Peer-supported storytelling}

In the fourth study, the intervention was "peer-supported storytelling" ${ }^{[27]}$. Storytelling involves an individual telling by one or more participants about an event or multiple events that touched the narrator. These events took place during a specific time period and included, for example, different people, contexts, and perspectives and the narrator's actions, thoughts, and feelings. The intervention included nurses from the pediatric oncology department who met in pairs every week for two months for talks using a conversation guide. They were invited to talk about the experience of caring for a child who was ill with cancer whose death was mourned. Each session lasted about 17 minutes and ended with questions designed to help the narrator to make sense of her/his experience. Measurements were taken before, during, and at the end of the intervention. Measures included three questionnaires developed by the researcher of the study: a demographic and professional losses questionnaire, a questionnaire for the report of professional losses during study, and an end-of-study evaluation questionnaire. Two standardized instruments were also used: the "Hogan Grief Reaction Checklist" (HGRC) and the "Inventory of Social Support" (ISS), which measure the perception of support for grief in five areas. A 5-point Likert-scale was used and each item was scored and summarized.

\subsubsection{Debriefing sessions}

The intervention in the fifth study was intended to examine the effectiveness of a debriefing method ${ }^{[28]}$. One hundred and thirteen debriefing sessions were performed during 2002 and 2005, which focused on the emotional reaction of the medical staff and their relationship with the patient, not just on death. Debriefing was offered within a week after the patient's death and was voluntary. The participants completed two questionnaires assessing quality improvement immediately after the intervention. One questionnaire ranked how useful, instructive, and meaningful the debriefing had been. In addition, a random survey measured how well the debriefing affected the nursing staff's ability to deal with sorrow and maintain their professional integrity.

\subsection{Effects of interventions}

The impact of the supportive interventions confirmed that education concerning pain and physical symptoms increased staff knowledge and self-confidence, but not their perceived anxiety, emotional exhaustion, or ability to manage existential crises. Staff experienced a sense of meaning and well-being when sharing experiences in conversation with a colleague, and grief becomes heavier and more difficult when a greater number of patients die.

\subsubsection{I ncreased understanding}

A number of interventions contributed to increased knowledge and understanding by the participants in several different ways ${ }^{[26,28,29]}$. First, nursing staff increased their practical knowledge about performing palliative care as well as understanding how other professionals perceived the child's terminal stage ${ }^{[26]}$. Ninety-eight percent of those who participated in debriefing sessions considered them to be informative and instructive ${ }^{[26,28]}$. It was statistically confirmed 
that education increases knowledge and the ability to understand and interpret pain signals, to provide good pain relief, to interpret and manage physical symptoms as well as promote increased awareness and reflectivity on ethical and legal issues. However, it could not be confirmed statistically that education increases health care professionals' ability to manage their own anxiety or to prevent emotional exhaustion. The staff also felt less competent after receiving education about the importance of providing clear, direct, and honest communication to families whose children are about to die ${ }^{\text {[29] }}$.

\subsubsection{I ncreased confidence}

It was statistically confirmed that health care professionals' confidence increased when they received education about pain and pain management techniques. Strategies to recognize and treat the child's various symptoms and to be more knowledgeable about ethical issues were also established. Health care professionals believe that it is easier to control physical symptoms than to deal with emotional or ethical issues, and therefore they feel more confident and secure when relieving the child's existing physical symptoms. Training with the intention to teach health care professionals how to manage an existential crisis or how they could prevent emotional exhaustion was reported to have had no statistically significant effect on their self-confidence. Neither did education about cultural differences and the importance of good communication, which instead had the opposite effect, making staff more uncertain. Education about spiritual matters did not contribute to an increased self-confidence because staff perceived that before the training they already had a high level of awareness about spiritual aspects when caring for dying children ${ }^{[29]}$.

\subsubsection{Creating meaning}

When a child died, health care professionals experienced the creation of a sense of meaning by sharing their experiences in conversation with a colleague. Participants described that during this conversation they had to probe their feelings and find something positive and meaningful about the incident. The opportunity to tell a colleague about difficult events contributed to the experience and what they learned from the situation became clearer. Participants also described how they acted professionally and how they would benefit in the future from the experience. By listening to other colleagues' experiences, they could draw parallels with what they had experienced and thus find meaningful aspects. Participants registered a high level of personal maturity on the HGCR scale after sessions of storytelling ${ }^{\text {[27] }}$. Ninety-eight percent of participants thought that counseling in the form of debriefing was meaningful because it gave them an opportunity to reflect on the individual child and their own role as a participant in the child's care. They also felt that the opportunity to debrief put the child's self-worth in focus and gave their work greater value ${ }^{[26,28]}$.

\subsubsection{Grief management}

Nurses estimated themselves low on the HGRC scale, including factors such as despair, panic, guilt, and anger, after sessions of storytelling. These sessions had no significant effect on grief over time. However, strong evidence suggests that health care professionals perceive that their grief gets heavier and more difficult when more patients die with whom they had developed a close relationship. One participant described the sessions of storytelling as a source of support for her to think through how she could cope with grief, but that they did not provide help to manage or alleviate it. However, this was possibly because she had already processed the grief on the two subjects she talked about during the sessions ${ }^{[27]}$. Alternatively, support in the form of debriefing increased staff's ability to cope with grief when they learned to work through their emotions by affirming and expressing them rather than suppressing them. The more debriefing sessions the staff were involved in, the better they found themselves dealing with their grief ${ }^{[28]}$. Staff did not consider that peer-supported interventions in the form of training and related discussions about grief reactions, coping strategies, and basic philosophies of pediatric palliative care increased their ability to cope with grief, nor did their perceived feeling of sadness decrease ${ }^{[25]}$.

\subsubsection{Sense of well-being}

Health care professionals described a sense of well-being when they were supported by various forms of conversation ${ }^{[26,27]}$. They described that it is being pleasant to talk with someone who had had similar experiences ${ }^{[27]}$ without being questioned or condemned ${ }^{[26,27]}$. Staff who participated in debriefing sessions stressed the importance of taking care 
of themselves and maintaining good communication with colleagues, patients, and family. They argued that a lack of communication compounded by confusion and insecurity could have a negative impact on their well-being ${ }^{[26,28]}$. Health care professionals expressed satisfaction in being able to support a colleague by taking time to listen to what she or he had

experienced ${ }^{[27]}$. Debriefing helped them to remain sharp in their profession despite difficult experiences ${ }^{[26,28]}$, although feelings of exhaustion due to work-related factors did not decrease after peer-support interventions ${ }^{[25]}$.

\section{Discussion}

The aim of this literature review was to describe interventions that support pediatric health care professionals to manage emotional strain when caring for children at the end-of-life. The articles reviewed in our study used interventions that were primarily person-focused and not directed towards care organizations. According to McVicar ${ }^{[29]}$, the care organizations have a responsibility to prevent job stress and burnout among staff, but knowledge of how sources of stress vary between different clinical settings and how staff and workplace factors interact is limited. To combine interventions on an individual and organizational level is critical to the prevention of stress among health care professionals ${ }^{[30]}$. Our review highlights that the most common supportive intervention to prevent distress among pediatric health care professionals was training in different forms of counseling, updating skill programs and debriefing. There is inadequate evidence that management interventions for supporting health care professionals reduce job stress and burnout, and further research is needed to assess if longitudinal interventions with booster sessions have more persistent effects ${ }^{\text {[31] }}$. In our review, education seemed to have a positive effect on staff's self-confidence and it is important that they have not only sound knowledge in their field but also that they feel comfortable and at ease in their professional role. According to Vachon ${ }^{\text {[32] }}$, the most useful coping strategy for dealing with work-related stress for health care professionals working in palliative care is to acquire the right skills and find their own professional role. One article in our review showed that debriefing with the aim to manage emotionally difficult situations seemed to be a positive support intervention. Our results also show that intervention studies within this specific area are lacking as well as evidence concerning the effects of emotional debriefing, however, it may be an important forum for health care professionals in dealing with their day-to-day care stress as well as when facing critical incidents such as a child's death. Models to manage critical incidents, such as the Critical Incident Stress Debriefing (CISD), are well described in the literature especially within emergency and psychiatric care ${ }^{[3,34]}$. This model ought to be of use for pediatric health care professionals caring for dying children as well but first needs to be verified within this context.

Feeling safe and comfortable when communicating with seriously ill children and their families is important to health care professionals. Communication is difficult but important and significant in the care, and communication difficulties are a known stressor for professionals. The use of particular language and of specific phrases has a major impact on how adult patients in palliative care interpret information. This does not mean that health care professionals necessarily use difficult medical terms, but rather, that certain words feel threatening or avoiding or make the person feel abandoned ${ }^{[35]}$. An increased knowledge and understanding of the difficulties of communication may be the reason that the health care professionals in our review felt less competent and more uncertain after receiving training in the area. However, there is research that shows that health care professionals in palliative care can improve their communication skills through education and training. We believe that an increased ability to communicate about emotionally charged subjects ultimately should lead to a reduction of health care professionals' emotionally-related stress.

Education was not a support for the health care professionals in managing an existential crisis or emotional strain, nor did it improve self-confidence and safety. Neither did discussions about the spiritual aspects of caring for dying children increase self-confidence. However, training contributed to an increased ability of the caregiver to reflect on ethical and legal issues. This means that it may not be possible to learn to deal with such grief theoretically or to prevent burnout, but discussions may be a support in identifying and managing emotions. However, research shows that interventions containing both training and opportunities for discussion and reflection on existential issues such as life, death, and 
meaning have a greater impact on health care staff's feelings of security when talking to dying adults. The staff's ability to make independent decisions increased and work-related stress was reduced ${ }^{[36]}$.

Dealing with grief and finding meaning in a child's death was facilitated, and debriefing was perceived as useful, instructive, and meaningful in the interventions identified in our study. Hecktman ${ }^{[37]}$ found that debriefing when nurses are dealing with stress is not routine in clinical pediatric work, but might occur spontaneously in the team in connection with a child's death or other traumatic events. Debriefing is originally a method of preventing psychological distress and post-traumatic stress disorder in survivors of sudden psychological trauma. It does not prevent the onset of post-traumatic stress or reduce psychological morbidity, depression, or anxiety, but rather, increases the risk of depression and post-traumatic stress disorder ${ }^{[38]}$.

Supportive conversations seem to increase health care professionals' well-being in several ways. They provide an opportunity to express feelings, to be listened to, acknowledged, and understood, and this opportunity is more important than the form in which these conversations take place. Emotional reactions are not a sign of defeat or weakness, but rather, a human and normal reaction. Health care professionals often perceive that when a child they care for dies, it is a failure and a defeat, and they react more strongly, emotionally, when a child they were particularly attached to dies. Reasons for this could be a lack of practice, knowledge, or ability to save the child's life and being an adult unable to protect the child from harm. Nurses even feel that they are betraying the parents because they cannot save the most valuable thing they have ${ }^{[39]}$. Health care professionals must have the time for conversations with the family; management understands that this is a natural part of the work and is an investment in improving the work environment. Organizational factors strongly contribute to work-related stress among health care professionals in palliative care ${ }^{[40]}$. There is also a direct correlation between what support is offered and how well the staff meet the demands of their work ${ }^{[41]}$. If the employer fails to meet the need for a supportive work environment, stress can be intensified with an increased risk of staff burnout. Organizations that support and value their staff may recognize that this results in increased job satisfaction and higher employee morale, which ultimately results in a higher quality of care ${ }^{[42]}$.

Health care professionals' well-being is always affected in the care of dying children; when they do not feel well, it is a great challenge to help them feel better. Without support and help, the emotional strain leads to emotional exhaustion. This can be a precursor to fatigue depression. Emotional exhaustion is common and an expected condition that affects health care professionals involved in providing care to people in crisis. The difficulty tends to increase over time and negatively affects their relationship with the patient and their family. Rourke ${ }^{[43]}$ has developed a framework of suggested strategies to avoid this condition. The proposals are based on the research available in areas other than pediatric palliative care but coincide well with the findings in our review. It is important for nurses to mourn patients who die, to focus on the positives of the experience, and to try to make sense of what happened. Regular support in peer groups in a safe and nonjudgmental environment with active listening as the focus, the creation of common goals, continuous professional development, and case-related training may prevent emotional exhaustion and fatigue depression.

\section{Methodological limitations}

Keywords were chosen based on the aim of the study and inclusion and exclusion criteria and broad searches were made to make sure that as many studies as possible were included. Included articles were discussed among the research team to ensure that no article was improperly rejected and that consensus was reached on the articles' content as a result of the translation from English to Swedish. The SBU assessment model ${ }^{[22]}$ was used as the criteria are clear and ensured that the articles were assessed and evaluated equally. This template ensured that relevant criteria were reviewed, clarifying the content of studies and their strengths and weaknesses. One major strength of this review is that a total of 1,770 health care professionals' views were included in these articles. However, there are certain limitations in this study as only five articles were found during literature searches and these were of medium or low quality and the interventions used were not validated or described in detail. In addition, the studies were all completed in the United States, providing only a Western 
care culture perspective. Despite these weaknesses, the studies included were considered to have important results and provide valid information about the state of knowledge within the area.

\section{Conclusion and implications for practice}

Specific recommendations supporting pediatric health care professionals' emotional and physical well-being are infrequent. These professionals are exposed to major emotional stress associated with the care of a dying child, which undermines their self-esteem, personal maturity, and well-being. To manage anxiety and prevent emotional exhaustion is challenging and having a clear, direct, and honest communication with families whose children are about to die is difficult. A combination of education and some form of conversation sessions seems to have positive supportive outcomes, but continuous debriefing might have the most impact. Health care staff search for meaning in difficult situations and questions of an existential nature are raised, which must be made visible in pediatric care.

\section{I mplications for research}

In the future it is important to perform qualitative hermeneutic research providing a deeper understanding of pediatric health care professionals' need of emotional support when caring for children at the end-of-life. The effects of randomized controlled interventions including debriefing specifically directed towards pediatric health care professionals' emotional strain must be further investigated.

\section{Conflict of interest}

The authors report no actual or potential conflicts of interests.

\section{References}

[1] Hinds P, Schum L, Baker JN, Wolfe J. Key factors affecting dying children and their families. J Palliat Med. 2005; 8 Suppl 1:70-78. PMid:16499471 http://dx.doi.org/10.1089/jpm.2005.8.s-70

[2] Contro N, Larson J, Scofield S, Sourkes B, Cohen HJ. Hospital staff and family perspectives regarding qualityof pediatric palliative care. Pediatrics. 2004 nov; 114(5 Part 1): 1248-1252. PMid:15520103 http://dx.doi.org/10.1542/peds.2003-0857-L

[3] McCloskey S,Taggart L. How much compassion have I left? An exploration of occupational stress among children's palliative care nurses. Int J Palliat Nurs. 2010 May; 16 (5): 233-240. PMid:20679971 http://dx.doi.org/10.12968/ijpn.2010.16.5.48144

[4] Morgan D. Caring for dying children: Assessing the needs of the pediatric palliative care nurse. Pediatr Nurs. 2009 Mars-April; 35(2): 86-92. PMid:19472671.

[5] Papadatou D, Martinson IM, Chung PM. Caring for Dying Children: A Comparative Study of Nurses' Experiences in Greece and Hong Kong. Cancer Nurs. 2001 Oct; 24(5): 402-412. PMid:11605711 http://dx.doi.org/10.1097/00002820-200110000-00013

[6] World Health Organization [WHO]. WHO Definition of Palliative Care. 2013[cited 2014 Aug 5]. Available from: http://www.who.int/cancer/palliative/definition/en/

[7] Ferlay J, Bray F, Pisani P, Parkin DM.GLOBOCAN. Cancer incidence, mortality and prevalence worldwide IARC CancerBase. 2002: No. 5[Internet]. Version 2.0. Lyon: IARC Press. 2004[cited 2014 Aug 5]. Available from: http://www-dep.iarc.fr/

[8] The National Board of Health and Welfare. (Cancer i siffror 2009. [Cancer in numbers 2009]. 2013[cited 2014 Aug 5] Available from: http://www.socialstyrelsen.se/Lists/Artikelkatalog/Attachments/8348/2009126-127_2009126127.pdf

[9] Central Bureau of Statistics. Barn- och familjestatistik. [Child and Family Statistics]. 2011[cited 2014 Aug 5]. Available from: http://www.scb.se/sv_/Hitta-statistik/Statistik-efter-amne/Levnadsforhallanden/Levnadsforhallanden/Barn--och-familjestatistik/

[10] Watson P, Feld A. Factors in stress and burnout among paediatric nurses in a general hospital. Cancer Nurs. 1994; 17(1): 61-71.

[11] Ernst ME, Messmer PR, Franco M, Gonzalez JL. Nurses' job satisfaction, stress, and recognition in a pediatric setting. Pediatr Nurs. 2004 May-Juni; 30(3): 219-227.

[12] Yam B, Rossiter J, Cheung K. Caring for dying infants: experiences of neonatal intensive care nurses in Hong Kong. J Clin Nurs. 2001 Sep;10(5): 651-657. PMid:11822516 http://dx.doi.org/10.1046/j.1365-2702.2001.00532.x

[13] Aycock N, Boyle D. Interventions to manage compassion fatigue in oncology nursing. Clin J Oncol Nurs. 2009 Apr; 13: 183-191. PMid:19349265 http://dx.doi.org/10.1188/09.CJON.183-191 
[14] Sabo BM. Compassion fatigue and nursing work: Can we accurately capture the consequences of caring work? Int J Nurs Pract. 2006 Jun; 12: 136-142. PMid:16674780 http://dx.doi.org/10.1111/j.1440-172X.2006.00562.x

[15] Fischer JE, Calame A, Dettling AC, Zeier H, Fanconi, S. Experience and endocrine stress responses in neonatal and pediatric critical care nurses and physicians. Crit Care Med. 2000 Sep; 28(9): 3281-3288. PMid:11008993 http://dx.doi.org/10.1097/00003246-200009000-00027

[16] Hinds PS, Quargnenti AG, Hickey S S, Mangum G H. A comparison of the stress response sequence in new and experienced pediatric oncology nurses. Cancer Nurs. 1994 Feb; 17(1): 61-71. PMid:8180978 http://dx.doi.org/10.1097/00002820-199402000-00007

[17] McCluggage HL. Symptoms suffered by life-limited children that cause anxiety to UK children’s hospice staff. Int J Palliat Nurs. 2006 Jun; 12(6): 254-258. PMid:16926735 http://dx.doi.org/10.12968/ijpn.2006.12.6.21450

[18] Taubman-Ben-Ari O, Weintroub A. Meaning in life and personal growth among pediatric physicians and nurses. Death Stud. 2008; 32(7): 621-645. PMid:18924291 http://dx.doi.org/10.1080/07481180802215627

[19] Lee KJ, Dupree CY. Staff experiences with end-of-life care in the pediatric intensive care unit. J Palliat Med. 2008 Sep; 11(7): 986-990. PMid:18788959 http://dx.doi.org/10.1089/jpm.2007.0283

[20] Moher D, Liberati A, Tetzlaff J, Altman DG. The PRISMA Group. Preferred Reporting Items for Systematic Reviews and Meta-Analyses: The PRISMA Statement. J Clin Epidem. 2009 Oct; 62(10): 10061012. PMid:19631508 http://dx.doi.org/10.1016/j.jclinepi.2009.06.005

[21] Cullum N. How to decide if review articles are trustworthy and relevant for practice. NT Learn Curve. 1997 Aug; 3(6): 4-6.

[22] SBU. Evidensbaserad omvårdnad vid behandling av personer med depressionssjukdomar. [Evidence-based nursing care in the treatment of people with depressive disorders]. 1999[cited 2014 Aug 5]. Available from: http://www.sbu.se/sv/Publicerat/Vit/Evidensbaserad-omvardnad-vid-behandling-av-personer-med-depressionssjukdomar/

[23] Willman A, Stoltz, P, Bahtsevani C.Evidensbaserad omvårdnad: en bro mellan forskning och klinisk verksamhet. [Evidence-based nursing: a bridge between research and clinical practice] (2d ed.). Lund: Studentlitteratur; 2006.

[24] Rogers S, Babgi A, Gomez C. Educational interventions in end-of-life care: part I: An educational intervention responding to the moral distress of NICU nurses provided by an ethics consultation team. Adv Neonatal Care (Elsevier Science). 2008 Feb; 8(1): 56-65. PMid:18300739 http://dx.doi.org/10.1097/01.ANC.0000311017.02005.20

[25] Eagle S, Creel A, Alexandrov A. The effect of facilitated peer support sessions on burnout and grief management among health care providers in pediatric intensive care units: A pilot study. J Palliat Med. 2012 Nov; 15(11): 1178-1180. PMid:22909377 http://dx.doi.org/10.1089/jpm.2012.0231

[26] Rushton CH, Reder E, Hall B, Comello K, Sellers DE, Hutton N. Interdisciplinary interventions to improve pediatric palliative care and reduce health care professional suffering. J Palliat Med. 2006 Aug; 9(4): 922-933. PMid:16910807 http://dx.doi.org/10.1089/jpm.2006.9.922

[27] Macpherson C. Peer-supported storytelling for grieving pediatric oncology nurses. J Pediatr Oncol Nurs. 2008 May-June; 25(3): 148-63. PMid:18413700 http://dx.doi.org/10.1177/1043454208317236

[28] Keene E, Hutton N, Hall B, Rushton C. Bereavement debriefing sessions: an intervention to support health care professionals in managing their grief after the death of a patient. Pediatr Nurs. 2010 Jul-Aug; 36(4): 185-189;quiz 190. PMid:20860257

[29] McVicar A. Workplace stress in nursing: a literature review. J Adv Nurs. 2003 Dec; 44(6): 633-642. PMid:14651686 http://dx.doi.org/10.1046/j.0309-2402.2003.02853.x

[30] Roberts RK, Grubb PL. The consequences of nursing stress and need for integrated solutions. Rehabil Nurs. 2014 Mar-April; 39 (2): 62-69. PMid:23696492 http://dx.doi.org/10.1002/rnj.97

[31] van Wyk, BE, Pillay-Van Wyk, V. Preventive staff-support interventions for health workers. Cochrane Database Syst Rev. 2010 Mar; 17(3): CD003541.pub2. Review.

[32] Vachon M. Caring for the caregiver in oncology and palliative care. Semin Oncol Nurs. 1998 May; 14(2): $152-157$. http://dx.doi.org/10.1016/S0749-2081(98)80021-1

[33] Wagner SL. Emergency response service personnel and the critical incident stress debriefing debate. Int J Emerg Ment Health. 2005 Winter; 7(1): 33-41. PMid:15869079

[34] Antai-Otong D. Critical incident stress debriefing: a health promotion model for workplace violence. Perspect Psychiatr Care, 2001 Oct-Dec; 37(4): 125-132. PMid:15521312 http://dx.doi.org/10.1111/j.1744-6163.2001.tb00644.x

[35] Friedrichsen MJ, Strang, PM, Carlsson ME. Cancer patients’ interpretations of verbal expressions when given information about ending cancer treatment. Palliat Med. 2002 Jul; 16(4): 323-330. PMid:12132545 http://dx.doi.org/10.1191/0269216302pm543oa

[36] Udo C, Danielson E, Henoch I, Melin-Johansson C. Surgical nurses’ work-related stress when caring for severely ill and dying patients in cancer after participating in an educational intervention on existential issues. Eur J Oncol Nurs. 2013 Oct; 17(5): $546-53$. PMid:23522827 http://dx.doi.org/10.1016/j.ejon.2013.02.002 
[37] Hecktman H M. Stress in Pediatric Oncology Nurses. J Pediatr Oncol Nurs. 2012 Nov-Dec; 29(6): 356-361. PMid:23087251 http://dx.doi.org/10.1177/1043454212458367

[38] Rose SC, Bisson J, Churchill R,Wessely S. Psychological debriefing for preventing post traumatic stress disorder (PTSD). Cochrane Database Syst Rev. 2002; (2): CD000560. PMid:12076399

[39] Papadatou D. Training health care professionals in caring for dying children and grieving families. Death Stud. 1997 Oct-Dec; 21 (6): 575-600. PMid:10179828 http://dx.doi.org/10.1080/074811897201787

[40] van Staa AL, Visser A, van der Zouwe N. Caring for caregivers: Experiences and evaluation of interventions for a palliative care team. Patient Edu Couns. 2000 Aug; 41: 93-105. http://dx.doi.org/10.1016/S0738-3991(00)00119-1

[41] Hulbert NN, Morrison VV. A preliminary study into stress in palliative care: Optimism, self-efficacy and social support. Psychol Health Med. 2006 May; 11(2): 246-254. PMid:17129912 http://dx.doi.org/10.1080/13548500500266664

[42] White D. The hidden costs of caring: what managers need to know. Health Care Manag (Frederick). 2006 Oct-Dec; 25 (4): $341-347$. http://dx.doi.org/10.1097/00126450-200610000-00010

[43] Rourke MT. Compassion fatigue in pediatric palliative care providers. Pediatr Clin North Am. 2007 Oct; 54(5): 631-644. PMid:17933615 http://dx.doi.org/10.1016/j.pcl.2007.07.004 